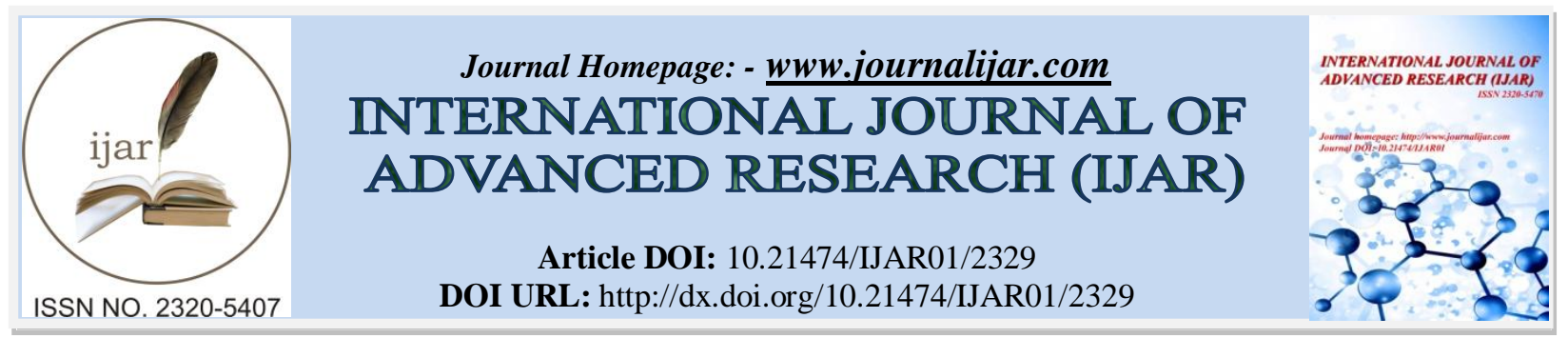

RESEARCH ARTICLE

\title{
STUDY OF SERUM INTERLEUKIN 17 LEVEL IN CHILDREN WITH BRONCHIAL ASTHMA.
}

"Mohammed Bazzari ${ }^{1}$, Iman Aly ${ }^{1}$ and Dalia Hassib ${ }^{2}$.

1. Department of Pediatrics, Banha University, Banha, Egypt.

2. Department of clinical pathology, Banha University, Banha, Egypt.

\section{Manuscript Info}

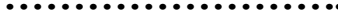

Manuscript History

Received: 30 September 2016

Final Accepted: 30 October 2016

Published: November 2016

\section{Abstract}

Background: Asthma is an inflammatory disease and is considered the most common chronic disease affecting children. In asthmatic airways, IL-17 serum level correlates with the incidence of airway hyperresponsiveness and the severity of the disease. Aim of this study was to find if there is significant increase in IL-17 serum level in asthmatic children and to study the correlation between the expression of IL-17 and that of total $\operatorname{IgE}$ in order to evaluate its role as a diagnostic tool.

Methods: Fifty children with bronchial asthma recruited from the Chest and Allergy clinic at pediatric department of Banha University Hospital from January first 2015 to 30 June 2015 and thirty-five apparently healthy controls were chosen for this study. ELISA tests were done for detection of serum level of IL-17 and IgE for all subjects.

Results: There is significant difference between asthmatic and control groups as regard to total IgE serum level $(\mathrm{p}=0.002)$ and $\mathrm{IL}-17$ serum level $(\mathrm{p}<0.001)$. There is insignificant positive correlation between IL17 and $\operatorname{IgE}(\mathrm{P}=0.15)$. The best cutoff values of $\mathrm{IL}-17>5.39$ (considered to be the level of asthma) with sensitivity $74 \%$ and specificity $80 \%$

Conclusion: There is significant difference in serum levels of IL-17 and total IgE between asthmatic and control groups in children.

Copy Right, IJAR, 2016,. All rights reserved.

\section{Introduction:-}

Bronchial asthma is considered one of the most common chronic inflammatory diseases affecting children and young adults and has high morbidity and mortality rate (Lemanske and Busse, 2010). Many cells and cellular elements such as mast cells, eosinophils, T lymphocytes, macrophages, neutrophils and epithelial cells play a role in the pathogenesis of asthma. Among these inflammatory cells, T lymphocytes play major roles (Harrington et al., 2011). IL-17 forms a family of cytokines that are produced by subset of effectors helper $\mathrm{T}$ cells with distinct functions from TH1 and TH2 cells (named TH17 cells). There have been reports of a significant increase in the frequency of TH17 cells in the peripheral blood of children with asthma compared with healthy controls. In asthmatic airways, IL-17 correlates with the incidence of airway hyper-responsiveness and the severity of disease. Specifically, IL-17 expression is enhanced in severe and chronic asthma (Alyasin et al., 2013). In addition, it has been demonstrated that TH2 and TH17 responses can act synergistically to promote bronchial asthma. Therefore, an improved understanding of the cellular and molecular mechanisms that regulate TH2 and TH17 effectors responses

Corresponding Author:- Mohammed Bazzari.

Address:- Department of Pediatrics, Banha University, Banha, Egypt. 
might lead to novel therapeutic strategies to prevent or control bronchial asthma (Kaminska et al., 2009; Kudo et al., 2012).

Immunoglobulin E is an antibody class. It is mainly synthesized in skin lymphoid tissue, respiratory tracks, bowel and lymph nodes, that provide their drainage. The main function of $\operatorname{IgE}$ is prevention of the body from helminths and protozoons. IgE is also very important in type I hypersensitivity shown by various allergic disorders, such as allergic asthma, allergic rhinitis, food allergy, atopic dermatitis, anaphylactic reaction etc (Galkin and Dugan, 2013). It is well known that there is a significant increased total serum IgE level in the serum of asthmatic patients (Kashiwakura et al., 2011).

In fact, Understanding the biology of IL-17 in the context of allergic inflammation may be informative in the development of novel approaches to the diagnosis and treatment of asthma (Wang and Wills-Karp, 2011). So we try to achieve better understanding of role of interleukin 17 in bronchial asthma, its relation to the severity of the disease and its relation to the other markers of the disease like IgE in order to help other studies to evaluate the role of IL-17 in diagnosis of asthma.

\section{Subjects and methods:-}

Subjects were divided into asthmatic group which consists of 50 asthmatics child which were selected from chest and allergy clinic of Banha university hospital from January first 2015 to 30 June 2015 and control group which included 35 apparently healthy Child of matched age and sex. Asthmatic children had to fulfill the criteria of asthmatic diagnosis of GINA guidelines 2014 (GINA 2014). All groups were subjected to full history taking and full clinical examination.

Peak expiratory flow rate measuring: It is a person's maximum speed of expiration, as measured with a peak flow meter. It is used to monitor a person's ability to breathe out air. It measures the airflow through the bronchi and thus the degree of obstruction in the airways. The highest of three readings was used as the recorded value of the Peak Expiratory Flow Rate. Peak flow readings were often classified into 3 zones of measurement according to the American Lung Association; green, yellow, and red. Asthma management plan is based on the green-yellow-red zones (Wikipedia 2012).

Laboratory Investigation: Routine laboratory investigation in the form of CBC, stool analysis, and urine analysis were performed. Enzyme-linked immunosorbent assay (ELISA) tests were used for detection of serum level of IgE andInterleukin 17.

Sampling: $5 \mathrm{ml}$ of peripheral venous blood samples were collected on sterile plain tube and were allowed to stand for $30 \mathrm{~min}$ at room temperature then centrifuged. Serum was immediately separated and stored at $-20^{\circ} \mathrm{C}$ until the time of analysis.

Interleukin-17: Purified Human IL-17 antibody is used to coat micro titer plate wells. When IL-17 is added to wells, combined antibody with horseradish peroxidase (HRP) labeled coat anti-Human become antibody - antigen enzyme-antibody complex. After washing Completely, Tetramethylbenzidine (TMB) substrate solution is added, TMB substrate becomes blue color At HRP enzyme-catalyzed, reaction is terminated by the addition of a sulphuric acid solution and the color change is measured spectrophotometrically at a wavelength of $450 \mathrm{~nm}$. The concentration of IL-17 in the samples is then determined by comparing the O.D. of the samples to the standard curve (WKEA 2016).Human IL-17 ELISA KIT (96T) was used. It was ordered from WKEA MED SUPPLIES Inc. 206 No 6 building, Chenguang, Qianjin st, Chaoyang District, Changchun 130012, China

$\boldsymbol{I g E}:$ In this procedure, the immobilization takes place at the surface of a microplate well through the interaction of streptavidin coated on the well and exogenously added biotinylated monoclonal anti-IgE antibody. Mixing of the antibody with a serum containing the native antigen forms an antibody-antigen complex. After a suitable incubation period, the complex is separated from unbound antigen by aspiration. Another antibody labeled with an enzyme is added. Another interaction occurs to form an enzyme labeled antibody-antigen-biotinylated-antibody complex on the surface of the wells. Excess enzyme is washed off via a wash step. A suitable substrate is added to produce color measurable with the use of a micro plate spectrophotometer. The enzyme activity on the well is directly proportional to the native antigen concentration. By utilizing several different serum references of known antigen concentration, a dose response curve can be generated from which the antigen concentration of an unknown can be ascertained 
(Monobind 2016).IgE Accubind ELIZA micro wells were used. They were ordered from Monobind, Inc. Lake Forest, CA (92630) USA.

Statistical: Statistical Package for Social Sciences (SPSS) version 19 software was used to analyze and tabulate collected data. Categorical data were presented as numbers and percentages. Quantitative data were expressed as mean and standard deviation. Chi square test (X2) was used to compare between 2 or more categorical groups. Student t-test, "Z" of Mann Whitney and U-test were used to compare means of two independent groups. Kruskal Wallis ANOVA was used to compare means of more than two independent groups. Pearsons correlation analysis and Spearman Rho correlation were used to compare between quantitative variables. Receiver operating characteristic (ROC) curve was used to detect the best cutoff value with optimum sensitivity and specificity. The accepted level of significance (predictive value) was $>0.05$.

Study approval: This study was approved by the ethics committee of Banha Faculty of Medicine. Written informed consent was received from participants prior to inclusion in the study. Participants were identified by number, not by name.

\section{Result:-}

IL-17: There was highly significant difference between asthmatic and control groups as regard to IL-17 levels ( $p>0.001$ ). It ranged from $0.7-445.5 \mathrm{pg} / \mathrm{ml}$ in asthmatic group with mean of $51.5 \pm 118.1$ while in control it was ranged from 2-97.9 $\mathrm{pg} / \mathrm{ml}$ and mean was $7.4 \pm 16$ Figurel. The receiver operating characteristic (ROC) curve for performance of IL-17 serum level in diagnosis of asthma showed that the best cutoff values of IL-17 was $5.39 \mathrm{pg} / \mathrm{ml}$ (considered to be the level of asthma) with sensitivity $74 \%$ and specificity $80 \%$ Figure 2.

IgE: This study shows a significant difference between asthmatic and control groups as regard to IgE level $(\mathrm{P}=0.002)$. It ranged from $7.5-419.3 \mathrm{iu} / \mathrm{ml}$ in asthmatic group with mean of $231 \pm 169.5$ while in control it was ranged from 10.1-419.3 iu/ml and mean was 106.1 \pm 120.8 Figure 3. Receiver operating characteristic (ROC) curve was used for detection of performance of IgE serum level in diagnosis of asthma as shown in Table 2. The best cutoff values of $\mathrm{IgE}=73.2 \mathrm{iu} / \mathrm{ml}$ (considered to be the level of asthma) with sensitivity $74 \%$ and specificity $58.8 \%$ Figure 4.

Correlation between II-17 and IgE: There was insignificant positive correlation between II-17 and IgE (Rho = 0.16, $\mathrm{P}=0.15$ ) Figure 5.

\section{Discussion:-}

Asthma is a chronic inflammatory disorder of the airways characterized by airway obstruction that is generally reversible and by hyper-responsiveness to a variety of stimuli (Skloot 2015). Many cells and cellular elements play a role in the pathogenesis of asthma. Among these inflammatory cells, T lymphocytes play major roles (Harrington et al., 2011). Previous studies indicate that pathological mechanisms of asthma involve more than just a dichotomous TH1/TH2 inflammation. Another subset of effectors helper T cells with distinct functions from TH1 and TH2 cells (named TH17 cells) has raised great interest. There have been reports of a significant increase in the frequency of TH17 cells in the peripheral blood of children with asthma compared with healthy controls. TH17 cells preferentially produce IL-17 family of cytokines (Alyasin et al., 2013). IgE is also very important in I type hypersensitivity shown by various allergic disorders, such as allergic asthma, allergic rhinitis, food allergy, atopic dermatitis, anaphylactic reaction etc (Galkin and Dugan, 2013). Previous studies reported that expression of IL-17 and IgE was higher in patients with bronchial asthma than those of healthy control and that there was a correlation between IL-17 and IgE, indicating their regulator role in the pathogenesis of bronchial asthma (Lu et al., 2012).

In this study we found a highly significant difference between asthmatic and control as regard to IL-17 level ( $p>0.001)$. The mean of serum IL-17 levels in asthmatic children was $(51.5 \pm 118.1) \mathrm{IU} / \mathrm{ml}$, while the mean of healthy control was $(7.27 \pm 15.83) \mathrm{IU} / \mathrm{ml}$. This agrees with previous studies in that asthma had higher levels of IL-17 in serum than the control group (Plé et al., 2015; Alavi et al., 2015; Jiang et al., 2013). Allergic asthmatics exhibit higher levels of IL-17 in the lung and sera than healthy subjects and the results was significant at $(\mathrm{P}<0.05)$ according to (Lu et al., 2012; Jiang et al., 2013) and (P0.01) according to (Min 2012). In contrast a previous study found that IL-17 was equally detected in the serum of patients with asthma and in that of the controls. It was explained that as the studies that reported the increase of IL-17were especially associated with more severe lesions of the disease. 
However, in their study, most patients had a mild or moderate form of the disease, and so IL-17 levels were similar to those observed in the controls (Lima et al., 2015).

In the current study there was a significant increase in serum total IgE levels in asthmatic than in control group $(\mathrm{P}<0.05)$, as the mean of serum total IgE levels in asthmatic children was $(231.02 \pm 169.52) \mathrm{IU} / \mathrm{ml}$, while the mean of healthy control was $(106.14 \pm 120.75) \mathrm{IU} / \mathrm{ml}$. This comes with other studies that found relatively low serum IgE levels of non-asthmatic, compared with asthmatic patients (Lu et al., 2012; Min 2012; Carvajal-Raga et al., 2015; Wanjun et al., 2011) and it was significant at ( $\mathrm{P}<0.05)$ according to (Lu et al., 2012) and at (P 0.01) according to (Min 2012; Wanjun et al., 2011). In fact, Increase in blood IgE levels has long been implicated in the development and severity of asthma (Wu et al., 2012).

In this study there was insignificant positive correlation between IL-17and $\operatorname{IgE}(\mathrm{P}=0.15)$. Previous studies showed that the mean production of IL-17 in bronchitis asthma was positively correlated to the production of $\mathrm{IgE}(\mathrm{Lu}$ et al., 2012; Min 2012). Correlation was significant at $(\mathrm{P}<0.05)$ according to ( $\mathrm{Lu}$ et al., 2012) and at $(\mathrm{P}=0.01)$ according to (Min 2012). Using ROC curve, our study specify the best cutoff values of IL-17 > 5.39 (considered to be the level of asthma) with sensitivity $74 \%$ and specificity $80 \%$ while the best cutoff values of $\operatorname{IgE}=73.2$ (considered to be the level of asthma) with sensitivity $74 \%$ and specificity $58.8 \%$.

In fact, understanding the biology of IL-17 in the context of allergic inflammation may be informative in the development of novel approaches to the diagnosis and treatment of asthma (Wang and Wills-Karp, 2011). Currently, several drugs that target IL-17 signaling are being tested in clinical trials. Several tries aim to find whether there are any specific features of this heterogeneous disease that potentially could be relieved by the use of IL-17-targeting drugs (Silverpil and Lindén, 2012).

Conclusion:

our study reveal that there was a significant increase in IL-17 and IgE serum levels in asthmatic group than in control children with a significant positive correlation between them. The best cutoff value of IL-17 was $>5.39$ with sensitivity $74 \%$ and specificity $80 \%$. This is indicating that IL-17 has a primary role in pathogenesis of bronchial asthma and that IL-17 with help of future studies can provide new lines for diagnosis and treatment of asthma.

\section{Author contributions:-}

Study was decided and designed by Eman Aly. The study was performed in Chest and Allergy clinic at Pediatric Department of Banha University Hospital by Mohammed Bazzari under supervision of Eman Ali. History was collected and clinical examination was performed by Mohammed Bazzari under supervision of Eman Ali. Specimens were collected from Participants by Mohammed Bazzari under supervision of Dalia Hassib. Laboratory investigations were performed in clinical labs of Banha University hospital by Dalia Hassib. Statistical analysis was perfomed by Mohammed Bazzari under supervision of Eman Ali and Dalia Hassib. Manuscript was written by Mohammed Bazzari under supervision of Eman Ali and Dalia Hassib.

\section{Acknowledgments:-}

First of all, All thanks and Glory is to Allah for His true Guidance and Aid that caused this humble work to become a reality.It is a pleasure to express great thanks and respect to Prof. Dr. Iman Abdel-Rehim;Professor of Pediatrics, Faculty of Medicine, Benha University, for her continuous encouragement, supervision, guidance throughout this work. We also wish to express deep gratitude to Dr. Dalia Mohamed Abd El Hassib;Lecturer of Clinical Pathology, Faculty of Medicine, Benha University, of her valuable suggestions, explanation and guidance throughout this work. Finally we express great thanks to our families which always support and stand beside us. 


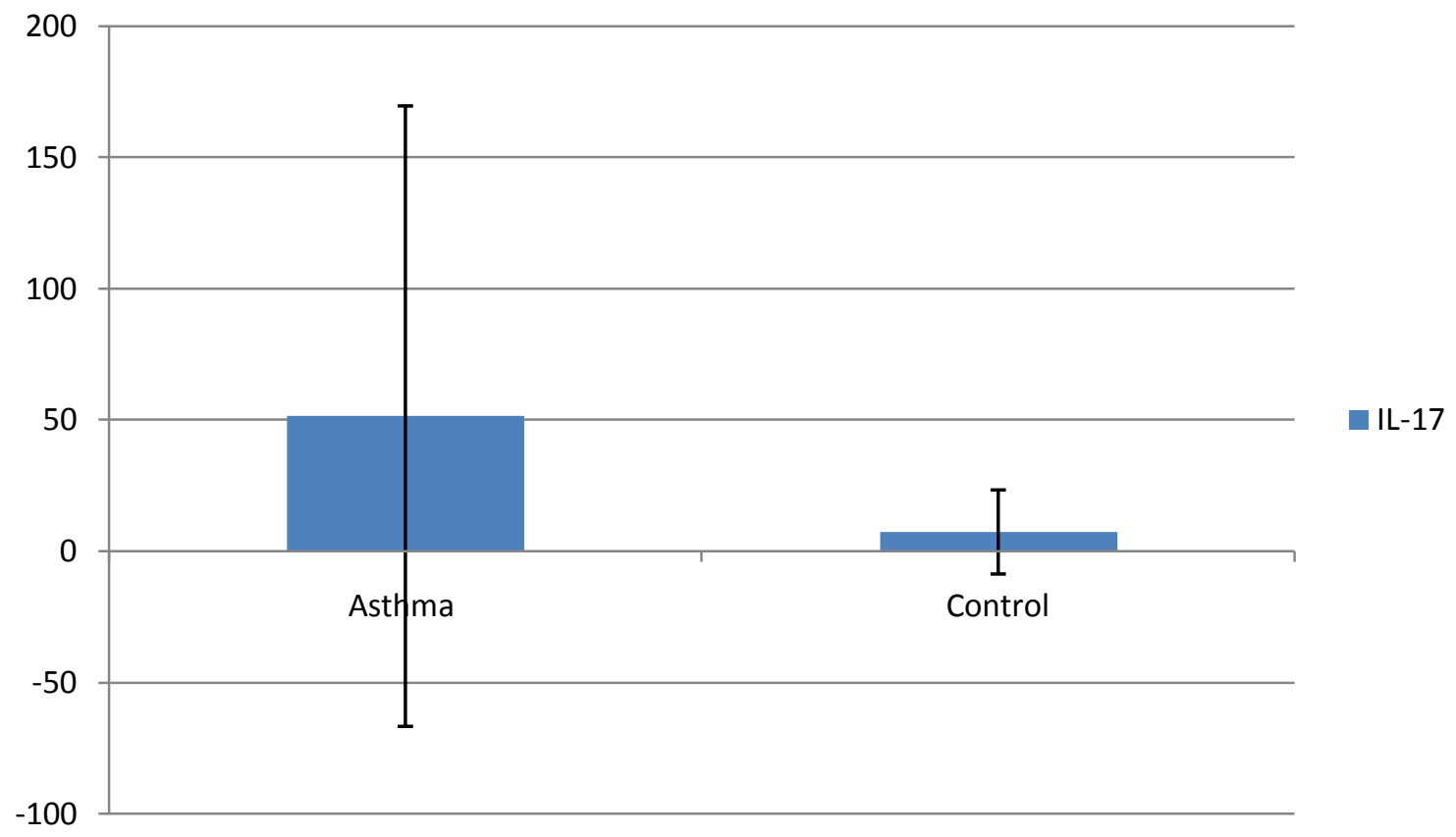

Figure 1:- Comparison between asthmatic and control groups, regarding IL-17 level.

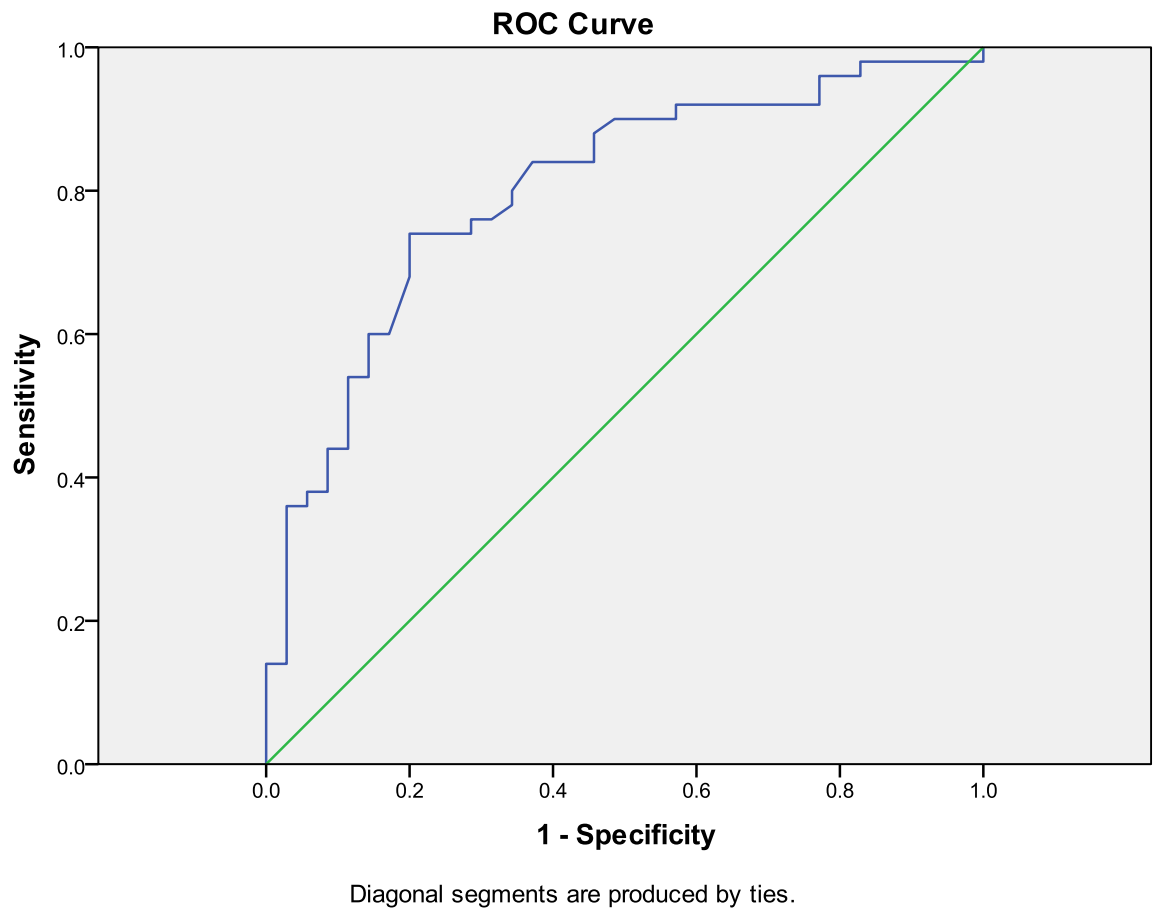

Figure 2:- ROC curve to define the best cut off value of IL-17. 


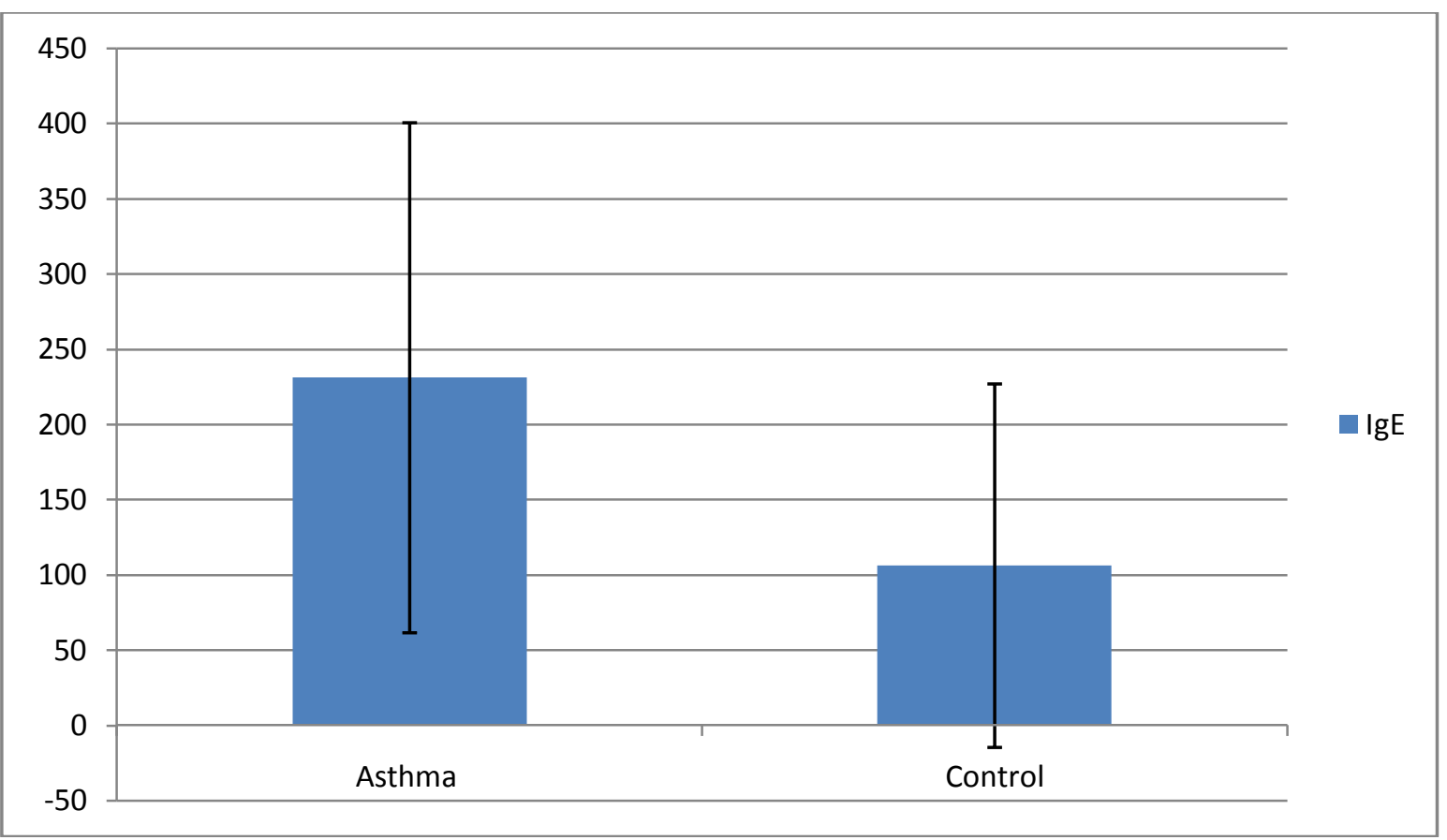

Figure 3:- Comparison between asthmatic and control groups, regarding IgE level.

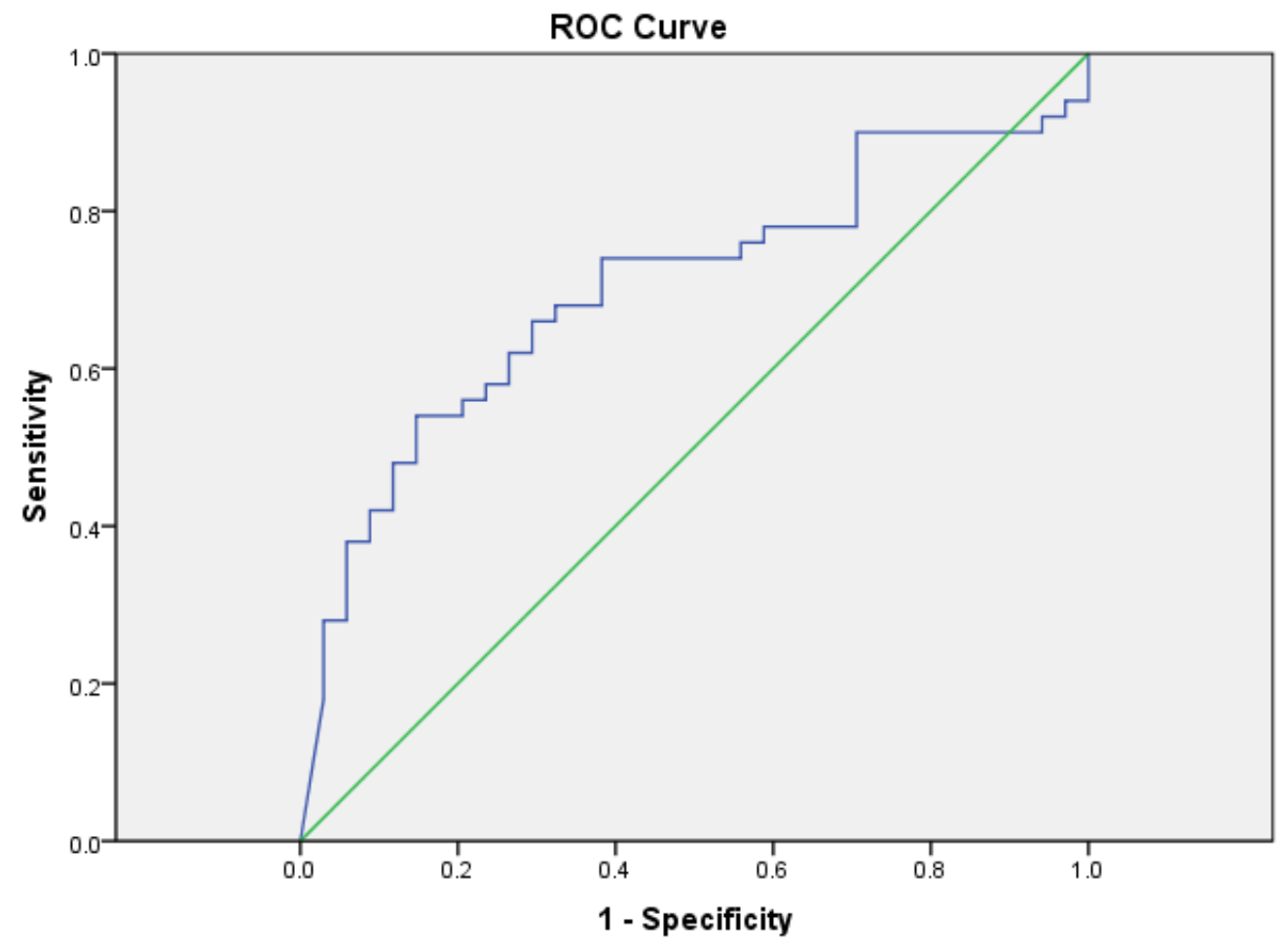

Diagonal segments are produced by ties.

Figure 4:- ROC curve to define the best cut off value of IgE. 


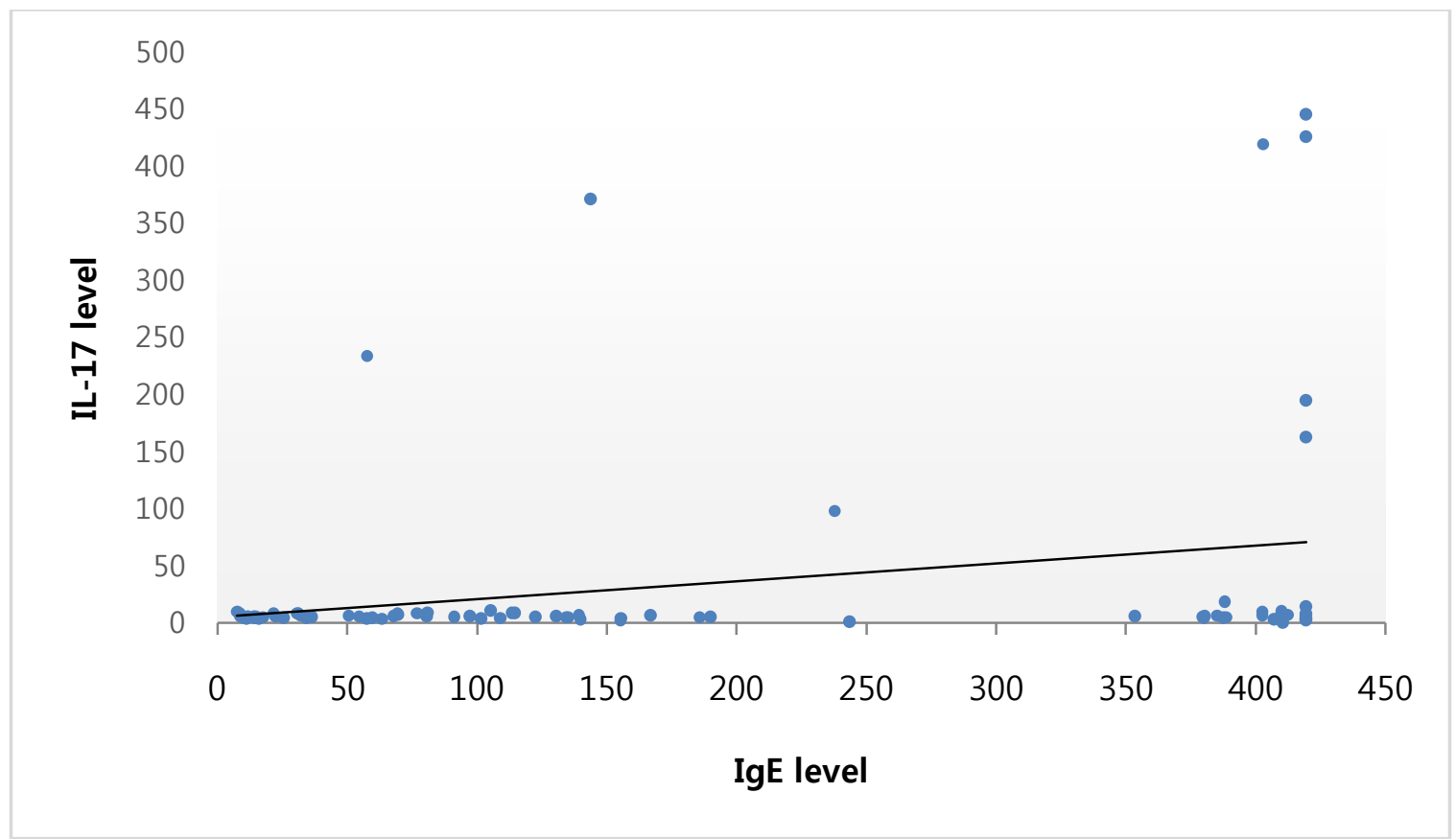

Figure 5:- Correlation between IgE and IL-17

\section{Reference:-}

1. Alavi, M.M., Nordlund, B., Thunberg, S., et al., (2015): Systemic IL-17 Signaling Relates to Gender, Disease Severity and Use of Oral Steroids in Children with Asthma. J Allergy Clin Immunol., 135(2): AB180.

2. Alyasin, S., Karimi, M.H., Amin, R., et al., (2013): Interleukin-17 Gene Expression and Serum Levels in Children with Severe Asthma. Iranian journal of immunology., 10(3): 177-185.

3. Carvajal-Raga, S.M., Kohlhoff, S., Weedon, J., et al., (2015): Non-Asthmatic Children Have Higher IgM AntiEnterovirus 71 and Lower IgE Levels, but Higher IL-2 and IL-4 Levels Than Asthmatic Children. J Allergy Clin Immunol., 135(2): AB112.

4. Galkin, A.Y. and Dugan, A.M. (2013): Elaboration of immunoenzymatic test-kit for total human IgE assay and investigation of its analytical properties. International Journal of Immunology., 1(1):1-6.

5. GINA (2014): Guide for Asthma management and prevention web site.

6. http://www.ginasthma.org/local/uploads/files/GINA_Report_2014_Aug12.pdf Updated August 2012. Accessed March 28, 2015.

7. Harrington, L.E., Hatton, R.D., Mangan, P.R., et al (2011): Interleukin 17-producing CD4+effector T cells develop via a lineage distinct from the T helper type 1 and 2 lineages. Nat Immunol., 6(11):1123-1132.

8. Jiang, K., Chen, H.B., Wang, Y., et al., (2013): Changes in IL-17 and TGF- $\beta 1$ levels in serum and bronchoalveolar lavage fluid and their clinical significance among children with asthma). Zhongguo dang dai er ke za zhi., 15(8): 604-608.

9. Kaminska, M., Foley, S., Maghni, K., et al (2009): Airway remodeling in subjects with severe asthma with or without chronic persistent airflow obstruction. J Allergy Clin Immunol., 124:45-51.

10. Kashiwakura, J., Otani, I.M. and Kawakami, T. (2011): Monomeric IgE and mast cell development, survival and function. Adv Exp Med Biol., 716:29-46.

11. Kudo, M., Melton, A.C., Chen, C., et al (2012): IL-17A produced by alphabeta T cells drives airway hyperresponsiveness in mice and enhances mouse and human airway smooth muscle contraction. Nat Med., 18:547-554.

12. Lemanske, R.F., and Busse, W.W. (2010): Asthma: clinical expression and molecular mechanisms. J Allergy Clin Immunol., 125(2):95-102.

13. Lima, J.S., Santos, R.S., Ribeiro, B.M., et al., (2015): Immune Response Profiles During Asthma Attacks and Intercriti-cal Periods In Children. Int J Clin Med Allergy., 3(3): 26-33.

14. Lu, H., Liu, L., Cheng, H., et al., (2012): Expression of interleukin 17 and IgE, and its significance in patients with bronchial asthma. Afr J Pharm Pharmacol., 6: 2828-2831.

15. Min, W.A.N.G. (2012): The correlation of ECP, IL-17 and IgE in serum of children with acute exacerbation of 
bronchial asthma. Chinese Journal of Aesthetic Medicine., 14, 068.

16. Monobind web site (2016): http://www.monobind.com/Products/immunoassays-allergy-ige. Accessed Feuarbry 8, 2016.

17. Plé, C., Fan, Y., Yahia, S.A., et al., (2015): Polycyclic Aromatic Hydrocarbons Reciprocally Regulate IL-22 and IL-17 Cytokines in Peripheral Blood Mononuclear Cells from Both Healthy and Asthmatic Subjects. PloS one., 10(4):e0122372.

18. Silverpil, E. and Lindén, A.(2012): IL-17 in human asthma. Expert Rev Respir Med., 6(2):173-186.

19. Skloot, G.S. (2015): Tests for Assessing Asthma. Allergy and Clinical Immunology., 77-81.

20. Wang, Y.H. and Wills-Karp, M. (2011): The potential role of interleukin-17 in severe asthma. Current allergy and asthma reports., 11(5): 388-394.

21. Wanjun, W., Jianping, C., Qin, G., et al., (2011): Importance of skin prink test and total serum IgE level in diagnosis of cough variant asthma in children. Journal of Third Military Medical University., 12: 21.

22. Wikipedia (2012): Peak expiratory flow web sitehttps://en.wikipedia.org/wiki/Peak_expiratory_flowUpdated April 2012. Accessed April 11, 2015.

23. WKEA web site (2016): IL-17. www.wkeamedsupplies.com Accessed Feuarbry 8, 2016.

24. Wu, C.C., Chen, R.F. and Kuo, H.C. (2012): Different implications of paternal and maternal atopy for perinatal IgE production and asthma development. Clin Dev Immunol., 